\author{
ANNALS OF THE \\ UNIVERSITY OF CRAIOVA
}

\author{
Series: $\checkmark$ Biology \\ $\checkmark$ Horticulture \\ $\checkmark$ Food products processing \\ technology \\ $\checkmark$ Environmental engineering
}

\title{
Vol. XXVI (LXII) - 2021 \\ TEMPERATE CLIMATE YIELD PLASTICITY AND PLATEAU PRODUCTION LEVELS OF CHANDLER WALNUT ORCHARDS TREATED WITH CAO AND ENRICHED SEAWEED EXTRACT ASCOPHYLLUM NODOSUM
}

\author{
Kalorizou Helen ${ }^{1 *}$, Papachatzis Alexandros ${ }^{1}$ \\ ${ }^{1}$ University of Thessaly, Department of Agriculture -Agrotechnology, Geopolis Campus, \\ 41500, Larissa Greece \\ ${ }^{*}$ Correspondence author: Email: hkalorizou@uth.gr
}

Keywords: Walnut, biostimulants, yield, calcium oxide, Ascophyllum nodosum

\begin{abstract}
This study was carried out to investigate the yield plasticity and plateau production levels of Chandler walnut orchards treated with / without two different types of biostimulants. CaO based and enriched seaweed Ascophyllum nodosum extract biostimulants were applied in optimum fertilized and irrigated chandler walnut orchards in order to defined their efficacy and contribution to temperate fruit production in Greece. No statistically significant differences were observed between biostimulant treated and non-treated walnut orchards in terms of yield and timing in maturing fruit process. Further investigation on the data concludes that Chandler walnut orchard yield proximity to plateau production levels due to pre-optimized fertilization eliminates potential benefits of biostimulants; yield increase potential in sub-optimum fertilized walnut orchards treated with above mentioned substrates remains high.
\end{abstract}

\section{INTRODUCTION}

Plant biostimulants consist a very important group of sustainable tools in order to enhance yield, resilience and quality in farming practices (Basile et al. 2020). Nowdays local and global recommendations for orchard management are focusing in environmentally friendly support of yield and fruit quality via natural extracts and nutritive element enriched preparations (Rouphael and Colla 2018; Rodrigues et. al. 2020). That route supports minimal environmental changes for commercial operational yields in fruit production mitigating climate change (Del Buono 2021). Biostimulants are not considered as fertilizers; in low concentrations induce a wide spectrum of biological activities in fruit trees due to their diverse bioactive substances (Du Jardin 2015). Two groups of the most common biostimulants in fruit production used in orchard practice are $\mathrm{CaO}$ based and enriched seaweed extracts such as Ascophyllum nodosum (Morales-Payan and Candelas 2014; Soppelsa et al. 2020). Few to zero information is known for biostimulant's use in highly productive walnut trees - such as Chandler orchards- which are deploying their fruit production in sunny temperate environments. Water availability, disease control and optimum fertilization of walnut trees are the main parameters of optimum yield growth (Drobek et al. 2019). In this work we investigate if under fully optimum agronomical conditions Chandler walnut orchards increase their yield when treated with the two above 
mentioned biostimulant preparations in Greece, willing to understand the outcome data for farm consulting purposes through the use of extensive research literature.

\section{MATERIALS AND METHODS}

Study Area: Experiments took place on Chandler walnut orchards (pollinator variety: Franquette) in the agricultural area of Chalki, Larisa, Greece $\left(39^{\circ} 34^{\prime} 13.54 " \mathrm{~N}, 2^{\circ} 30^{\prime} 57.87^{\prime \prime} \mathrm{E}\right)$ in 2020 . Temperature and precipitation information was obtained according to the climate bulletins of the Hellenic National Meteorological Service Data Center for the full area of Larisa (http://www.hnms.gr/emy/en/climatology/climatology_month) and local farming meteological network data of Chalkis GR, collected and analyzed by National Observatory of Athens (https://www.noa.gr/en/, https://www.meteo.gr, https://www.meteofarm.gr/). In Chalki farming area the annual average temperature, annual maximum temperature, and annual minimum temperature were $17.45^{\circ} \mathrm{C}$, $30.5^{\circ} \mathrm{C}$, and $7.45^{\circ} \mathrm{C}$ respectively. The annual average rainfall, annual maximum rainfall, and annual minimum rainfall were $32.99 \mathrm{~mm}, 53.31 \mathrm{~mm}$ and $12.67 \mathrm{~mm}$ respectively. The study area is extremely sunny and optimum for Chandler walnut tree growth and temperature differences between day and night are very suitable for the growth of nuts. Experimental area was full of water reserves and it was fully equipped with drip irrigation systems to fulfil walnut trees requirements. For the annual fertilization program, Chandler walnut trees received $N(150 \mathrm{~kg} / \mathrm{ha}$, in three installments), P (50 Kg/ha) and $\mathrm{K}(140 \mathrm{Kg} / \mathrm{ha})$. The walnut trees on the experimental site did not have recorded incidences with micronutrient deficiencies in the past; no deficiencies were observed within the experimentation period. Experimentation site belongs to integrated pest management practices farming area.

Biostimulants: Calcium oxide was applied in concentration of $12 \% \mathrm{w} / \mathrm{w}$. Seaweed extract Ascophyllum nodosum was supplemented with nutritive elements (N, P, K, Na, Mg, Ca, S, Fe, B, Zn, Co, Mn, Cu, Mo), vitamins (B1, B2, PP, C, A, D, $\mathrm{E}, \mathrm{K}$ ) and aminoacids (aspartic acid, serine, glycine, glutamic acid, threonine, alanine, valine, methionine, leucine, lysine, tyrosine). Biostimulants were applied by spray deposition on leaves, as it follows: for calcium oxide, one application on the volume of $1 \mathrm{lt} / \mathrm{ha}$ and for enriched $A$. nodosum seaweed extract, two applications with 15 days interval on the volume of 1 lt/ha each, all at fruit setting period.

Experimental design: Twelve rows (12) of twenty-one (21) trees each in mature age and in capacity of full production were treated with active calcium oxide or enriched seaweed $A$. nodosum biostimulant and studied in relation to non-treated control. Harvest of fruits took place in two rounds based on the maturity stage of each fruit. Thereafter, weight of fresh fruits as a whole (pericarp, endocarp) was measured. Hulls removed and the weight of endocarp measured. Hulling walnuts were placed in drying chamber with $32^{\circ} \mathrm{C}$ temperature for 35 hours to reduce kernel moisture where dry matter was measured. Data from two harvest rounds were pooled in order to measure the net agronomic effect of biostimulant treatment on the tree rows.

Data Analysis: Data were analyzed using the 95\% confidence limit overlap protocol (Sokal and Rohlf, 1969), using software Prism 7.0 (GraphPad Software Inc.). A minimum of four replicates were used unless stated otherwise.

\section{RESULTS AND DISCUSSION}

Experimentation site meteorological data suggest that there was no environmental stress on the tested walnut trees (Table 1). Water availability by 
rainfall and irrigation practices were optimum for walnut orchard intensification. Wind during April - May 2020 resulted optimum conditions for pollination $(1,2 \pm 0,2 \mathrm{~km} / \mathrm{h})$.

Table 1

Walnut Chandler trees, experimental site environmental conditions (Chalki, Larisa GR)

\begin{tabular}{|c|c|c|c|c|c|c|c|c|c|c|c|}
\hline $\mathrm{I}$ & $\mathrm{F}$ & $M$ & A & $M$ & $\mathrm{~J}$ & $\mathrm{~J}$ & $A$ & $\mathrm{~S}$ & $\mathrm{O}$ & $\mathrm{N}$ & $\mathrm{D}$ \\
\hline \multicolumn{12}{|c|}{$T_{\operatorname{Min}}\left({ }^{\circ} \mathrm{C}\right)$} \\
\hline-3.6 & -1.2 & 0.4 & 3.6 & 9.9 & 13.7 & 19.7 & 18.2 & 14.2 & 9.3 & 1.8 & 3.7 \\
\hline \multicolumn{12}{|c|}{$\mathrm{T}_{\text {Mean }}\left({ }^{\circ} \mathrm{C}\right)$} \\
\hline 6.1 & 9.9 & 12.1 & 14.7 & 21.3 & 25 & 27.7 & 27.3 & 24 & 18.5 & 12.2 & 10.6 \\
\hline \multicolumn{12}{|c|}{$T_{\operatorname{Max}}\left({ }^{\circ} \mathrm{C}\right)$} \\
\hline 19.5 & 21.9 & 25.7 & 30.6 & 39.4 & 38.2 & 39.6 & 38.8 & 39.5 & 30.3 & 21.6 & 19.2 \\
\hline \multicolumn{12}{|c|}{ Wind $_{\text {mean }}(\mathrm{Km} / \mathrm{h})$} \\
\hline 1.1 & 1.8 & 1.5 & 1.4 & 1.0 & 1.1 & 0.9 & 0.9 & 0.8 & 0.5 & 0.3 & 0.3 \\
\hline \multicolumn{12}{|c|}{ Rainfall (mm) } \\
\hline 1.2 & 17.8 & 57 & 48.6 & 32.1 & 19.8 & 15.8 & 43 & 71.2 & 41.2 & 9.4 & 38.8 \\
\hline
\end{tabular}

Application of calcium oxide and enriched seaweed $A$. nodosum did not affect the weight of fresh fruits as no statistically significant differences were found between treatments among them and with non-treated control $(p=0.8143)$ (fig. 1a). The mean value of fresh fruits weight was $604.36 \mathrm{~kg}, 633.40 \mathrm{~kg}$ and $614.96 \mathrm{~kg}$ for control, calcium oxide and seaweed extract respectively. There were no statistical differences between treatments in fresh weigh of hulling nuts and untreated control $(p=0.823)$ (fig. 1b). The weight of nuts varied from $201.6 \mathrm{~kg}$ for control to $210.42 \mathrm{~kg}$ for trees sprayed with calcium oxide.
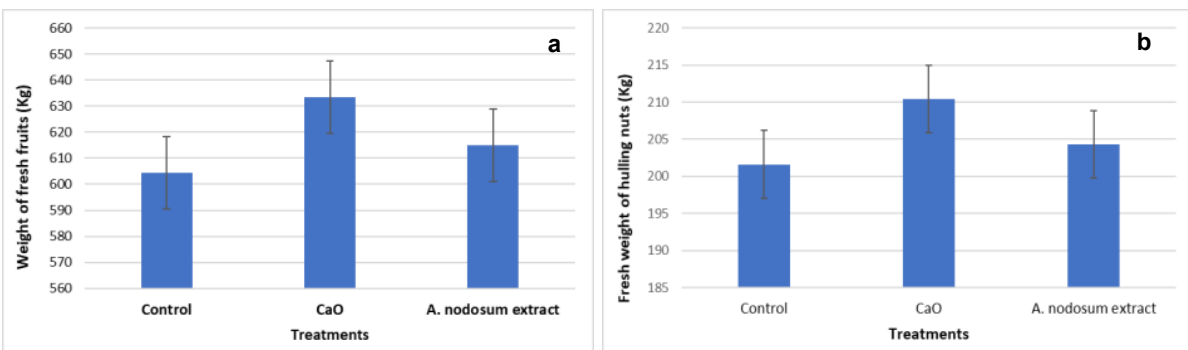

Figure 1. Walnut Chandler variety a) fresh fruit yield per treatment, b) fresh nut yield without hull per treatment (non-treated, $\mathrm{CaO}$, enriched $A$. nodosum extract respectively).

Calcium oxide and enriched seaweed $A$. nodosum extract application did not increase the dry weight of nuts as the dry weight of fruits were not statistically significant compared with untreated control $(p=0.823)$ (fig. 2a). The mean value of nuts dry weight was $145.6 \mathrm{Kg}, 151.97 \mathrm{Kg}$ and $147.56 \mathrm{Kg}$ for control, calcium oxide and enriched seaweed $A$. nodosum extract respectively. The fresh weight of fruits pericarp was found to be similar between treatments and untreated control $(p=0.809)$. In experimental walnut tree rows, fruits had mean pericarp weight value of $422.99 \mathrm{Kg}$ (calcium oxide treated), $410.63 \mathrm{~kg}$ (enriched seaweed $A$. nodosum 
treated), 402.76 (non-treated control); however no statistically significant differences on pericarp weight were apparent among treatments and in comparison, to nontreated control.
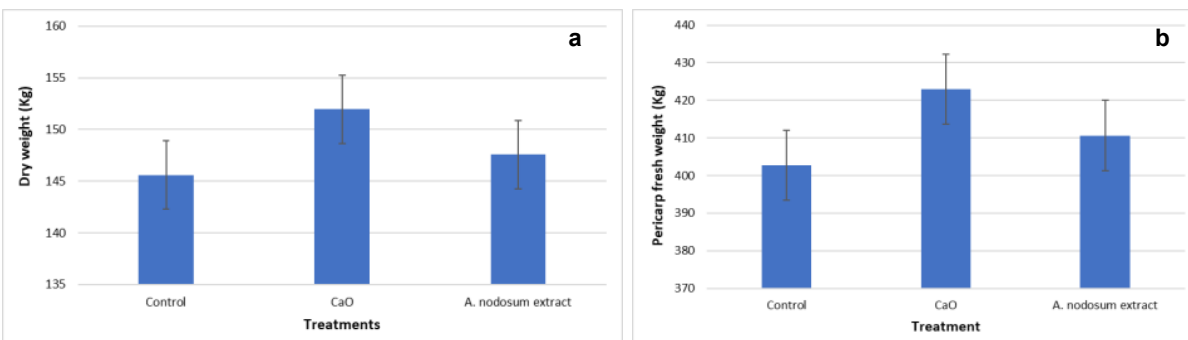

Figure 2. Walnut Chandler variety a) dry nut yield per treatment, b) fruits pericarp fresh weight per treatment (non-treated, $\mathrm{CaO}$, enriched $A$. nodosum extract respectively).

No differences in yield between treated and non-treated Chandler walnut trees with calcium oxide biostimulant may due to nutritional status of the trees. Fully irrigated and fully supplemented by soil calcium trees do not demonstrate quantitative yield changes, neither calcium defiencies in Chandler walnut tree tissues (Wilbur et al. 1992). Calcium deficiencies with effect in walnut physiology are rare due to $\mathrm{Ca}^{+2}$ soil availability by cation exchange (Ramos 1998). In tree tissues, continuously optimum calcium levels suggest: a) optimum cell structure and cell division b) optimum functionality of $\mathrm{Ca}^{+2}$ transporters / efflux pumps in the cellular membranes and c) optimum stress signaling responses whenever it is needed (Tuteja and Mahajan 2007). In various biological processes in plants such as spatial plant acclimatization, calcium seems to provide consistent -memory like - response (Knight et al. 1996). In other tree species, with tropics as optimal cultivation zone, such as avocado, applications with calcium oxide enhances reproductive characteristics of the tree and resistance in soil pathogens (Messenger et al. 1997). Climatic zone and rainfall sites (e.g. tropics) play significant role in variability of calcium concentration on tree tissue (Lira-Martins et al. 2019). Potentially, in these cases calcium oxide may have a boosting effect on growth, propagation and fruit yield/maturity.

Nutritive elements enriched seaweed $A$. nodosum extracts while applied on Chandler walnut trees did not demonstrate boosting effects on plant growth and fruit yield. In most cases like strawberry plants and grapevines, A. nodosum extracts alleviate stress effects on growth, fruit production and disease management; these observations do not refer to orchards with maximum / plateau performance yields (Shukla et al. 2019). For the plant model organism Arabidopsis thailiana and grapevine, extract from $A$. nodosum minimizes drought stress effect by boosting stomatia functionality and enhancing photosynthetic genes expression (Tombesi et al. 2021, Santaniello et al. 2017). Furthermore, oxygen reactive species damages due to salinity stress could be minimized when plant tissues treated with $A$. nodosum extracts (Shukla et al. 2018; Staykov et al. 2021). Herein, there was no stress conditions set on Chandler walnut trees in order to be relieved by $A$. nodosum biostimulant.

The results of this work are useful to define the operational limits of biostimulants in Chandler walnut orchards, especially in temperate, Mediterranean 
climates like the one in Greece. Biostimulants promote tree growth and fruit production, when problematic environmental conditions - or extreme weather conditions - take place. Under this viewpoint, biostimulants could be considered as alleviation stress tools, providing functional solutions in commercial pomology. However direct foliar application in orchard trees is not the only beneficial way to achieve farming sustainable goals; lately extracts of $A$. nodosum revealed to be supportive in endomycorrhization processes in plants (Hines et al. 2021). Further work needs to be done in walnut physiology in order to define biostimulants use in pre-optimized orchards where stress gene networks and oxidative stress are not in synergy and action, in order to promote fruit sustainability and farming resilience.

\section{CONCLUSION}

Under optimum conditions calcium oxide and enriched $A$. nodosum extract did not provide a yield breakthrough in Chandler walnut trees. It is possible that biostimulants use in this work may help trees to reach maximum - plateau yield in suboptimal and stressed conditions. Further research needs to take place not only on the previously mentioned environmental conditions, but also on the way that biostimulants are administrated on walnut trees, in order to expand potential avenues in sustainable and resilient walnut production.

\section{REFERENCES}

Basile B., Rouphael Y., Colla G., Soppelsa S., Andreotti C. 2020. Appraisal of emerging crop management opportunities in fruit trees, grapevines and berry crops facilitated by the application of biostimulants. Scientia Horticulturae, 267: 109330.

Del Buono D. 2021. Can biostimulants be used to mitigate the effect of anthropogenic climate change on agriculture? It is time to respond. Science of The Total Environment, 751: 141763

Drobek M., Frąc M., Cybulska J. 2019. Plant biostimulants: Importance of the quality and yield of horticultural crops and the improvement of plant tolerance to abiotic stress-A review. Agronomy, 9: 335.

Du Jardin P. 2015. Plant biostimulants: Definition, concept, main categories and regulation. Scientia Horticulturae, 196: 3-14.

Hines, S., van der Zwan, T., Shiell, K., Shotton K., Prithiviraj B. 2021. Alkaline extract of the seaweed Ascophyllum nodosum stimulates arbuscular mycorrhizal fungi and their endomycorrhization of plant roots. Sci Rep 11: 13491.

Knight H., Trewavas A.J., Knight M.R. 1996. Cold calcium signaling in Arabidopsis involves two cellular pools and a change in calcium signature after acclimation. Plant Cell., 8: 489-503.

Lira-Martins D., Humphreys-Williams E., Strekopytov S., Ishida F.Y., Quesada C.A., Lloyd J. 2019. Tropical tree branch-leaf nutrient scaling relationships vary with sampling location. Front. Plant Sci. 10:877.

Morales-Payan J.P., Candelas C.D. 2014. Increasing organic avocado fruit yield using a Ascophyllum Nodosum biostimulant and fertilization. Acta Hortic. 1042: 121-124.

Messenger B., Menge J.A., Amrhein C., Faber B. 1997. The effects of calcium on avocado growth and root health. California Avocado Society, Yearbook 81: 69-78.

Ramos D. 1998. Walnut Production Manual. University of California, Division of Agriculture and Natural Resources, Publication No 3373, 330p.

Rodrigues M., Baptistella J.L.C., Horz D.C., Bortolato L.M., Mazzafera P. 2020. Organic plant biostimulants and fruit quality-A review. Agronomy, 10: 988 
Rouphael Y., Colla G. 2018. Synergistic biostimulatory action: designing the next generation of plant biostimulants for sustainable agriculture. Front. Plant Sci., 9: 1-7.

Santaniello A., Scartazza A., Gresta F., Loreti E., Biasone A., Di Tommaso D., Piaggesi A., Perata P. 2017. Ascophyllum nodosum seaweed extract alleviates drought stress in arabidopsis by affecting photosynthetic performance and related gene expression. Front. Plant Sci. 8:1362

Shukla P.S., Borza T., Critchley A.T., Hiltz D., Norrie J., Prithiviraj B. 2018. Ascophyllum nodosum extract mitigates salinity stress in Arabidopsis thaliana by modulating the expression of miRNA involved in stress tolerance and nutrient acquisition. PLOS ONE 13(10): e0206221.

Shukla, P.S., Mantin, E. G., Adil, M., Bajpai, S., Critchley, A. T., Prithiviraj, B. 2019. Ascophyllum nodosum-based biostimulants: Sustainable applications in agriculture for the stimulation of plant growth, stress tolerance, and disease management. Frontiers In Plant Science, 10, 655

Soppelsa, S., Kelderer, M., Testolin, R., Zanotelli, D., Andreotti, C. 2020. Effect of biostimulants on apple quality at harvest and after storage. Agronomy, 10(8), 1214.

Staykov N.S., Angelov M., Petrov V., Minkov P., Kanojia A., Guinan K.J., Alseekh S., Fernie A.R., Sujeeth N., Gechev T.S. 2021. An Ascophyllum nodosumderived biostimulant protects model and crop plants from oxidative stress. Metabolites, 11:24.

Tombesi S., Frioni T., Sabbatini P., Poni S., Palliotti A. 2021. Ascophyllum nodosum extract improves leaf thermoregulation by reducing stomatal sensitivity to VPD in Vitis vinifera L.. J Appl. Phycol., 33: 1293-1304.

Tuteja N., Mahajan, S. 2007. Calcium signaling network in plants: an overview. Plant signaling \& behavior, 2: 79-85

Wilbur R., Sibbett S., Ramos D. 1992. Walnut Cultivar Nutritional Evaluation. An annual research report submitted to the California Walnut Board, p. 271-283. 